\title{
BARRAS BRAVAS Y TIEMPOS BRAVOS: VIOLENCIA EN EL FÚTBOL PERUANO
}

\section{Hardcore fans in hardcore times: violence in peruvian soccer}

\author{
Manuel Arboccó de los Heros* y Jorge O’Brien Arboccó**
}

\begin{abstract}
Resumen
El fenómeno de las barras bravas es un serio problema social en el país desde hace aproximadamente dos décadas. En los últimos años el problema parece desbordar a la población y al propio Estado. Algunos proponen solamente medidas policiales y punitivas, otros en cambio apelan a un discurso académico para intervenir desde las raíces mismas de los problemas de violencia familiar y social que sufren muchas sociedades llamadas modernas. En el siguiente artículo se definirá el problema, se analizarán sus causas y consecuencias, se recordarán algunos casos penosos de víctimas y victimarios y se propondrán finalmente algunas recomendaciones desde una perspectiva multidisciplinaria para enmendar la dificil situación.
\end{abstract}

Palabras clave: Violencia social, violencia en el fútbol, fanatismo, barras bravas, despersonalización, corrupción.

\begin{abstract}
The phenomenon of the barras bravas is already a problem in the country for approximately two decades. In recent years, the problem seems to overflow to the population and to the State itself. Some propose only measures police and punitive. Others, however, point to an academic speech to intervene from the roots of the problems of family and social violence suffered by many so-called modern societies. The present article will define the problem, its causes will be analyzed and consequences be remembered. Some cases painful for victims and perpetrators, and will finally propose some recommendations, from a multidisciplinary perspective to amend the difficult situation.
\end{abstract}

Keywords: Social violence, soccer violence, fanaticism, hooligans, depersonalization, corruption.

* Psicólogo. Profesor Universitario. Egresado de la Maestría en Psicología por la Universidad Nacional Mayor de San Marcos. Psicoterapeuta Humanista. manoloarbocco@gmail.com

** Psicólogo Social. Docente. Egresado de la Universidad Nacional Mayor de San Marcos. jorgeobrien@ outlook.com 
"Los deportes promueven la salud mental, la paz del espíritu...pueden aliviar las hostilidades naturales, la agresividad y la competitividad. Reducen la delincuencia, la criminalidad y la violencia"

(Singer, 1975)

\section{CONCEPTOS GENERALES: LA "BARRA BRAVA"Y SUS CARACTERÍSTICAS}

El concepto de "barra brava" se emplea en América Latina para designar a aquellos grupos organizados dentro de una hinchada que se caracterizan por producir diversos incidentes violentos dentro y fuera del estadio. Originalmente se les llamó "barra fuerte" (Diario la Razón, Argentina, 1958). Diego Fernando Bolaños nos recuerda que en otros contextos como el brasilero se conocen como "torcidas", en el argentino se les da el nombre de "Barras Bravas" mientras que en el europeo se distinguen como "Hooligans" (Gran Bretaña).

Este es el apelativo común con el que se conocen a los grupos de jóvenes, en su mayoría, que se ubican en las graderías de las tribunas populares (por el costo de la boleta y porque quienes las frecuentan comúnmente corresponden a sectores populares de las ciudades) y que haciendo gala de dicho espacio llevan a cabo grandes manifestaciones carnavaleras y aproximadas a lo que Maffesoli llama orgiásticas (Fernando Bolaños, 2007).

Dentro de los problemas que observamos con el comportamiento de estas barras y los problemas relacionados a ellas podemos indicar:

- Agresión (verbal y física) a árbitros.

- Agresión a jugadores e hinchadas rivales.

- Actos racistas dentro del fútbol.

- Vandalismo dentro y fuera de los estadios.

- Disputas dentro de las propias barras (mafias que buscan tomar el control absoluto de la barra).

- Heridos con arma blanca y con armas de fuego.

- Muertos.

- Los barristas más fuertes y que lideran el grupo obtienen ingresos de parte del club y de los jugadores. Esta situación, a pesar de ser conocida, se niega.
- Consumo y comercialización de drogas.

- Existe una disputa por una identidad, por un imaginario y un territorio simbólico (y a veces real).

- Pocos detenidos y ausencia de responsables.

- La situación va en aumento desde hace unos años.

- Las barras están en la búsqueda de aumentar su número de integrantes para con ello fortalecer al grupo, hacerlo más temido y desplegar una mayor presencia en las tribunas de su equipo.

- Este fenómeno se ha trasladado hacia otras regiones del país. Las famosas filiales de las barras de Lima. Así como a algunas ciudades de países vecinos, "las filiales internacionales".

- Hay cada vez mayor presencia de mujeres jóvenes en las tribunas populares, sectores caracterízados por la presencia de las barras bravas. Estas chicas forman parte, como enamoradas o amigas, de los barristas, exponiéndose a todas las consecuencias de formar parte de una barra brava.

- En los últimos años se viene denunciando el intento de delincuentes organizados (negociantes de drogas, cobradores de cupos en el sector de construcción civil, sicarios) de infiltrarse y tomar control de las barras bravas más importantes del país.

- Inseguridad ciudadana los días de partidos de fútbol. Las barras bravas suelen adueñarse de muchos sectores de la capital, sobre todo las zonas cercanas a los estadios. Antes, durante y después del partido esos lugares son altamente peligrosos.

\section{PRINCIPALES BARRAS BRAVAS EN EL PERÚ}

En este trabajo nos vamos a centrar en las barras de los dos equipos más populares del país: Alianza Lima y Universitario de Deportes. 
La barra del club Alianza Lima, es llamada el Comando Sur, fue fundada el 26 de octubre de 1986, los principales grupos que lo conforman son: Barraca Rebelde, La Calle, Los Sicarios, Callao Grone, Coalición, Cercado Grone, los Hooligans, Nekropsia. La barra del club Universitario de Deportes es llamada Trinchera Norte y fue fundada el 9 de noviembre de 1988. Los principales grupos que la conforman se autodenominan: La Turba, La Tropa, Secuaces, Los del Triunfo, Holocausto, La Bulla, Justicia, La Causa, Chicago. En ambos casos, cada uno de estos grupos pertenece a un distrito de Lima, zona que buscan liderar o en al argot callejero "batutear", lo cual significa dominar la zona y no permitir que hinchas de otros equipos aparezcan y menos que hagan notar su presencia o "figuren". Al interior de las hinchadas se produce un fenómeno de segmentación novedosa: grupos particulares identificados con nombres propios y organizados, con reparto de roles y funciones, con banderas propias, líderes y espacios físicos donde se ubican (como la facción de "Los Sicarios", dentro de la tribuna sur se ubica en el sector medio alto de la misma, es ya desde hace tiempo "su lugar").

Existe un denominador común en las costumbres de las barras bravas, citaremos algunas de ellas:

- Caminatas. Recorridos realizados camino al estadio donde juegue el equipo, desde tempranas horas y "raqueteando" los barrios a medida que avanzan. "Raquetear" significa revisar, vigilar que todo marche bien, "limpio" de otras barras. Citamos a Garriga Zucal (2006): Por esto planifican la forma de llegar a los estadios contrarios de la manera que más le duele al adversario, profanando el territorio ajeno, "caminándole el barrio".

- Visitas a barrios de fanaticadas rivales con el fin de pintar sus paredes, destruir sus casas y agredir a sus integrantes

- Pintas en muros, paredes, fachadas, con frases alusivas a su propio grupo junto con insultos al rival. Una suerte de "marcado" territorial: "Nosotros estuvimos aquí, en tu barrio y lo pintamos, nos pertenece $y$ no pueden detenernos". Debemos mencionar aquí que en la actualidad las barras bravas suben a internet (youtube.com y algunos foros) muchos vídeos mostrando y demostrando sus "actividades". Asimismo, las barras bravas cuentan con sus respectivas páginas web y cuentas en redes sociales.

- Robos de camisetas, polos y banderas rivales, considerados como "trofeos de guerra".

- Realizar el "espectáculo" en la tribuna: la llamada fiesta con globos, papeles picados, luces de bengala, juegos pirotécnicos, banderolas, etc. Actividad que ha decaído en la actualidad debido a que la policía viene prohibiendo el ingreso del material que genera el espectáculo para así evitar pueda filtrarse, entre banderas y bengalas, el ingreso de armas o demás sustancias prohibidas.

- Viajes acompañando al equipo hacia otras regiones del país y, en algunas oportunidades, al extranjero. Muchas veces solventados con apoyo de las directivas de los clubes (aunque se niega).

- La realización de actividades sociales como "polladas", fiestas y conciertos para recaudar fondos para sus polos, banderas nuevas o los viajes acompañando al equipo y para la adquisición de entradas. También para celebrar sus aniversarios y tener fondos para curar a sus "heridos" luego de los enfrentamientos con barras rivales.

\section{ALGUNAS TRISTES ESTADÍSTICAS LIMEÑAS:}

En febrero del 2012 el Secretario Técnico del Consejo Nacional de Seguridad Ciudadana (Conasec), Eduardo Pérez Rocha, informó que a partir de un estudio realizado el año 2009 en 42 distritos de Lima Metropolitana y 7 del Callao se descubrió que existen aproximadamente 22.000 pandilleros en 410 grupos de los tipos barrial, deportiva y escolar (Fuente: Entrevista a Radio Programas del Perú).

El también ex director de la Policía Nacional del Perú comunicó que el $45 \%$ de los pandilleros son menores de edad, el 38\% tiene entre 18 y 24 años, y el $17 \%$ entre 24 y 40 años. Asimismo, el $49 \%$ de estos individuos vive con sus padres, el $28 \%$ solo con la mamá, el $5 \%$ solo con el papá, y el $18 \%$ con otros familiares. El $70 \%$ de ellos no estudia. 
El fenómeno de las barras bravas está relacionado directamente con el fenómeno de las pandillas barriales quienes asumen una identidad colectiva ya sea detrás de un equipo o de una zona determinada de Lima, comúnmente el lugar donde viven. Cada una de estas pandillas tiene entre 15 y 100 miembros por grupo, lo que las hace muy peligrosas.

Las zonas de Lima donde se congregan más pandillas son: Villa María del Triunfo, San Juan de Lurigancho, Callao, Comas, Los Olivos, La Victoria, Villa el Salvador, San Martín de Porres, entre otros. Son responsables de atracos callejeros, robos calificados, destrucción de propiedad privada, venta de drogas y homicidios. Un caso conocido fue el sucedido en el año 2009 cuando fue intervenido el domicilio de un líder de barra de Universitario apodado "El gordo Bu" encontrándose gran cantidad de droga, con lo que se le inició un proceso penal. También es conocido que en el sector de construcción civil existen miembros que intentan ingresar a las barras con el fin de extorsionar y cobrar cupos.

\section{CASUÍSTICA (ALGUNOS BREVES EJEMPLOS DE LOS ÚLTIMOS 25 AÑOS):}

- (1988) La barra brava del Alianza Lima ingresa al estadio "Lolo Fernández" de Universitario de Deportes, saqueándolo y generando destrozos, esto después de jugado un Clásico en otro recinto deportivo, el Estadio Nacional.

- (1991) Barristas de Universitario queman el bus que movilizaba a los jugadores del Sporting Cristal en las afueras del Estadio "Lolo Fernández", luego de un partido entre ambas escuadras. Ningún jugador quedó herido pero el bus quedó totalmente incendiado.

- (1997) Con ocasión del partido entre Universitario de Deportes y Sport Boys, barristas de ambos equipos se enfrentaron con piedras y palos en las inmediaciones del Estadio Nacional. Muere un hincha de Universitario de Deportes.

- (1999). El cabecilla de la pandilla Las Quenas, de San Juan de Lurigancho, e integrante de la barra brava Comando Sur de Alianza Lima, J.A.P.M. (21años), fue detenido por haber disparado al menor de edad (14 años) R.R.S.R. miembro del bando Las Violetas de la barra rival, quien falleció.

- (2000) Pepito y la bengala: caso del niño asesinado por una bengala lanzada desde otra tribuna durante el partido entre Universitario de Deportes y Unión Minas de Cerro de Pasco. (Debemos resaltar que el sujeto que lanzó la bengala era miembro de las Fuerzas Armadas mientras que el fallecido era el hijo de una humilde vendedora de golosinas. No hubo ninguna sanción ejemplar para quien lanzó la bombarda).

- (2006) El vendedor de golosinas y declarado hincha de Universitario de Deportes, J.I.P.L. (22 años), fue asesinado a puñaladas por miembros de la pandilla "Los Choches" vinculados a la barra brava del Alianza Lima.

- (2007) Accidente fatal en Chimbote: Un Clásico del fútbol peruano entre Alianza Lima y Universitario trasladado hacia dicha ciudad con el fin de evitar enfrentamientos de consideración, dejó heridos y un hincha del Alianza Lima muerto por un accidente automovilístico producto de una emboscada por parte de barristas del club Universitario.

- (2008) Parte de la barra brava del Alianza Lima balea a hinchas de Universitario en Comas (1 muerto y 7 heridos)

- (2009) Caso Paola Vargas, joven profesional lanzada desde una unidad de transporte en movimiento mientras barristas de un mismo cuadro (Universitario) peleaban en su interior. La joven murió en el acto.

- (2009) Policías heridos por la barra de Universitario en las afueras del Estadio Monumental de Ate.

- (2010) Balaceras en el Estadio Lolo Fernández entre miembros de la barra de Universitario, por el control de la misma.

- (2011) Gresca entre barras de Universitario y del Sport Boys en el interior del estadio Monumental a vista y paciencia de los pocos policías que asistieron a ese partido. Muchos hinchas del Sport Boys resultaron seriamente heridos.

- (2011) Caso Walter Oyarce, asesinado en el mismo estadio Monumental de Ate, al finalizar un Clásico entre Alianza y Universitario. El 
hincha aliancista fue lanzado desde un palco tras una pelea entre barristas rivales.

- (2012) Un joven hincha (F.C.H. 24 años) de Universitario de Deportes murió apuñalado por unos pandilleros que formarían parte de una barra brava de Alianza Lima en el barrio de José Gálvez en Villa María del Triunfo.

- (2012) Cuando se dirigía al Estadio Nacional para ver el clásico, J.E.G.F. (20 años) fue interceptado en la zona de Pista Nueva por barristas de Universitario, quienes le dispararon a la altura de la garganta quitándole la vida.

- (2013) Un adolescente peruano fue asesinado por hinchas del Alianza Lima por andar con la camiseta de la 'U'. El hecho ocurrió en el centro de Santiago de Chile.

- (Abril del 2013) Barristas de Alianza Lima (Los Aliados de SJL) asesinaron a un joven mototaxista hincha de Universitario (C.M. C.R. 18 años) mientras se encontraba almorzando en el distrito de Comas.

- Por lo anteriormente expuesto observamos que en los clásicos Los clásicos del fútbol peruano entre Alianza Lima y Universitario siempre generan heridos y detenidos en cualquier estadio donde el partido se juegue, asimismo existe una pugna constante por el control interno de las barras de Alianza Lima y de Universitario, incluyen heridos y muertos.

Repetimos: estos son algunos casos de los últimos años, los heridos y muertos por la violencia entre barras bravas (todas, no solo las de Alianza Lima y Universitario) son muchos más.

\section{POSIBLES CAUSAS DEL FENÓMENO DE VIOLENCIA EN EL FÚTBOL PERUANO}

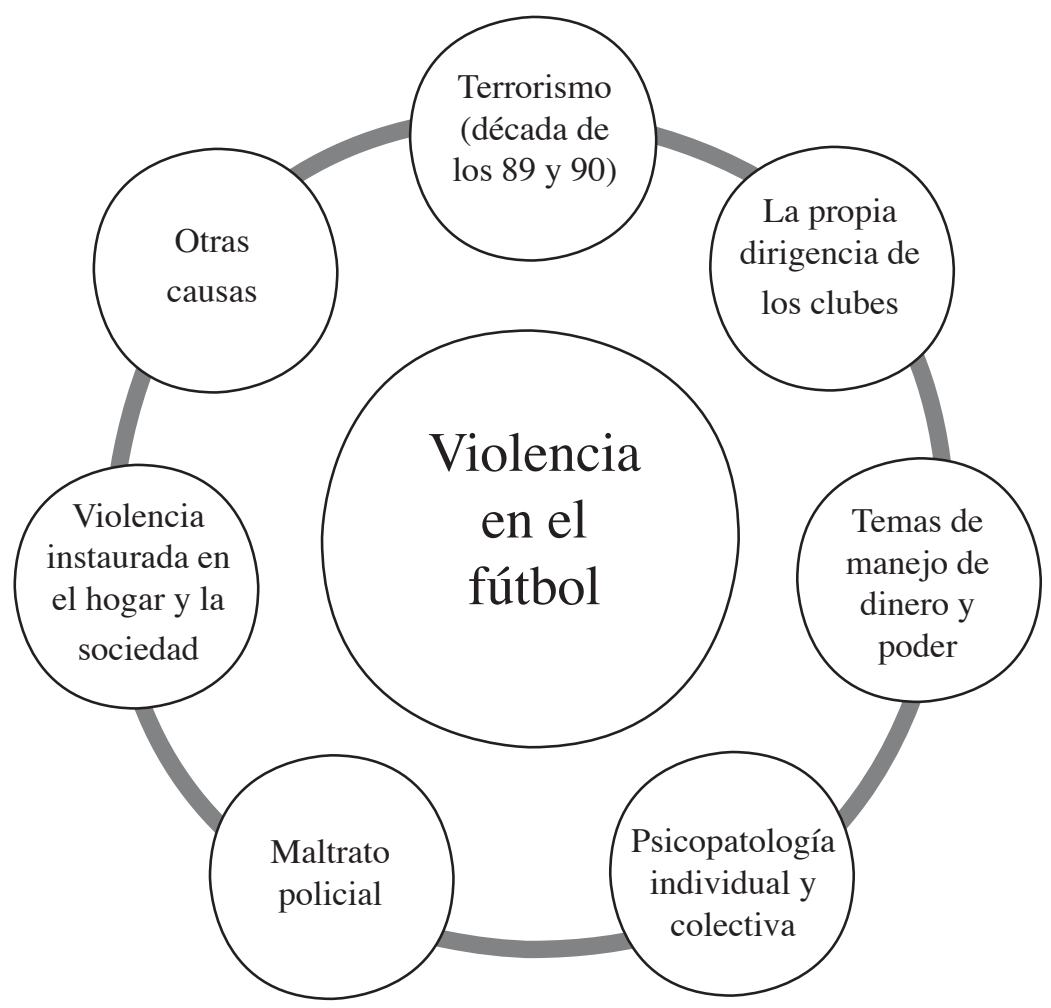

Gráfico 1: Causas de la violencia en el fútbol peruano. Elaborado por los autores, 2013 
Son variadas las causas de este problema social (Romero, 1986). Consideramos varios aspectos que van de lo personal a lo colectivo, de lo socio afectivo a lo ético moral, de lo institucional hasta lo más biológico personal. Los años de violencia que vivió el país en la guerra interna que se dio entre el Estado y los movimientos terroristas fueron generando no solamente muertos, viudas, huérfanos y mutilados sino toda una gama de dolor, una ola de depresión, miedo y resentimiento del cual a duras penas la población viene saliendo. Las conclusiones de la Comisión de la Verdad y la Reconciliación son claras: muchos niños sobrevivientes tras lo ocurrido se fueron alimentando de ese miedo, de esa frustración y generando deseos de venganza ante la incapacidad del Estado de sanar las heridas de ellos y de sus familias. Hay en las barras mucha presencia de jóvenes provincianos, son esos jóvenes a los cuáles el largo brazo del terror los alcanzó o sufrieron de cerca sus consecuencias. No es propósito de este artículo revisar las consecuencias de la guerra interna pero invitamos también a la revisión del informe mencionado. Como ejemplo tenemos a la ciudad de Ayacucho, golpeada durante años por el terrorismo y ahora está convertida en uno de los departamentos con una de las tasas más alta de pandilleros en el Perú.

La propia dirigencia de los clubes es parte del problema, pues camuflan, ocultan y hasta han llegado, en algunas ocasiones, a brindarles asesoría y apoyo legal a algunos de los cabecillas de estas agrupaciones. Es difícil separar, muchas veces, la paja del trigo, sin embargo, debemos, llegado este punto, especificar que en las tribunas populares existen también los hinchas y líderes de barras organizadas que simplemente buscan crear un clima de fiesta y celebración por el espectáculo en su tribuna y trabajan de manera organizada con las dirigencias y la policía nacional, con el fin de evitar actos delincuenciales como robos o agresiones, así pues, debemos diferenciarlos de los pseudo barristas que en complicidad con pésimos dirigentes deportivos -no los vamos a mencionar aquí con nombres y apellidos pero todos sabemos quiénes son y de los tentáculos en el poder que extendieron- saltan las normas, los códigos de seguridad y el buen comportamiento dentro y fuera de una tribuna y bajo pretexto de un partido dan rienda suelta a su comportamiento disocial. Conocido es en el medio deportivo el caso de dirigentes que financian a seudo barristas y a sus líderes. Todos estos "favores" son luego cobrados a cambio de seguridad personal o por el pedido de presionar a ciertos jugadores y hasta al técnico (D.T.) cuando ya no gozan de la confianza del dirigente.

Dentro de las barras existe una lucha interna por la jefatura pues las dirigencias de los clubes suelen entregar entradas sin costo alguno (cientos o miles de ellas) antes de los partidos y estas suelen ser revendidas a las afueras de los estadios consiguiendo lucrar de esta manera con estos ingresos. ¿A dónde van a parar estos ingresos? ¿Sólo al líder o a los líderes de las barras? ¿O van mitad y mitad con estos seudo dirigentes?

Existen sujetos con manifestaciones psicopatológicas claras, personajes con nulo control de impulsos, conducta disocial, con deficiente educación y carentes de un proyecto de vida. Provienen de familias disfuncionales y con otros problemas internos como violencia, adicciones, inmoralidad. Esto da pie a que muchas veces la barra brava sea un pretexto para dar rienda suelta a sus odios, resentimientos, frustraciones y deseos de venganza. El fútbol, como deporte masivo y popular, ofrece la ocasión ideal para promover las identidades colectivas, que, muchas veces, solapan la ausencia de identidades individuales, las cuales están debilitadas o ausentes por los problemas familiares y sociales que rodean al delincuente de una barra brava. (Benavides y colbs, 1998). El fútbol, la tribuna, el estadio es un espacio imaginario en el cuál operan a la vez la identificación grupal y la posibilidad simbólica de matar al otro, por la fuerza superior que brinda la barra: anonimato y cantidad de personas. Para el psicoanálisis, al no tratarse de una muerte real, puede renovarse simbólicamente en cada enfrentamiento. Y cada semana se repiten las mismas historias, aunque como sabemos, el nivel de violencia va siempre en aumento. En esta lógica, ante una afrenta recibida no podemos sino responder con la misma intensidad o con mayor nivel de violencia. La de nunca acabar.

Por su parte la policía es despreciada y atacada. Muchas veces provocan sin razón aparente a justos y pecadores -como dice el refrán popular- y están involucradas en actos de corrupción con las mismas barras bravas. Aquí cabe mencionar también el 
deficiente trabajo de los miembros del sector judicial, que permiten que detenidos por la policía en flagrante delito salgan libres después de sospechosas resoluciones o la simple imposición de débiles condenas.

La policía suele ver con mucho desagrado a los barristas pues por ellos son obligados a trabajar los fines de semana y tener que hacer operativos muchas horas antes, durante y después del enfrentamiento futbolístico. Este desagrado es percibido por los barristas, según nos comentaron algunos de ellos en entrevistas.

También está el jugador de fútbol que suele recurrir a la violencia como forma tonta, aunque efectiva, de compensar su escaso talento y ganarse algunos aplausos y consideraciones de los hinchas. Confunden esfuerzo y compromiso con violencia al rival y al árbitro para así ganarse representatividad y afiliación con el barrista y los colores del equipo a quien dice “defender". Muchas veces es solo una postura ante las cámaras.

Finalmente está el mal uso de ciertos sectores del periodismo, jugadores y dirigentes que se muestran poco alturados a la hora de declarar y que ensalzan con sus comentarios la violencia del hincha, o al considerar en sus titulares y notas de prensa a un partido de fútbol como una cuestión de Estado o "de vida o muerte".

\section{SITUACIONES PSICOSOCIALES QUE PROMUEVEN LA ACTITUD VIOLENTA DEL "BARRA BRAVA"}

"La probabilidad de la violencia de los espectadores en el contexto del fútbol está probablemente exacerbada por el grado en el que los espectadores se identifican con los equipos participantes y con la intensidad de su inversión emocional y su compromiso con la victoria de los equipos a los que alientan" Eric Dunning (1999)

Consideramos las siguientes como causas de la actitud violenta de un "barra brava":

- Integrantes provenientes de familias disfuncionales.
- Habituación a la violencia como medio de representatividad, reconocimiento y hacerse respetar.

- Conductas adictivas reforzadas en grupo.

- Pobreza. Si bien el fenómeno de las barras bravas no es exclusiva de sectores económicamente marginales, pues hay barristas de sectores pudientes (recordemos a algunos de los asesinos de Walter Oyarce), se debe considerar a la pobreza económica, educativa y moral como una de sus causas.

- Desempleo y falta de educación en valores sociales y morales.

- Predisposición biológica a la psicopatía (algunos jóvenes dijeron que disfrutaban de las peleas o "guerreos" con otros bandos, señalando que eso los excitaba).

- Poca tolerancia y amplia cantidad de frustraciones de diversos tipos: económicas, educativas, culturales, intelectuales, sexuales, raciales, etc.

- Falta de modelos de autoridad bien definidos. Por ejemplo, un trabajo de Mejía Navarrete con pandilleros en Lima indicó en entrevistas directas la poca presencia del padre en la familia o una presencia percibida por ellos como fría, distante, dictatorial, agresiva (Mejía Navarrete, 2005).

- Falta de grupos de referencia adecuados. Todo gira en ellos alrededor del grupo barrial o de la pandilla. Existe una identificación muy fuerte con el equipo de fútbol por encima de la familia, la escuela, el país (Alabarces, 1996). debido a que el Estado, la familia y la escuela no son ya para ellos fuentes de valores sino desvalores y nadie se vincula con sus representantes.

- Inmadurez de sus integrantes. Suelen ser muy jóvenes y cada vez lo son más.

- Ignorancia, deficiencias intelectuales y morales para tomar consciencia y responsabilidad de sus decisiones y acciones.

- Búsqueda de poder por medio de la violencia, la intimidación y el miedo.

- El efecto de despersonalización. Tema bastante estudiado por la psicología social y por autores como Phillip Zimbardo (1969); está el hecho de encontrarse dentro de una muchedumbre donde el sentido de responsabilidad individual 
se pierde, siendo difícil atribuirle a una persona las consecuencias de los daños cuando se encuentra en un grupo en un momento de desorden generalizado. Como nos recuerda Ortega Olivares, (2008) al formar parte de una barra el "yo individual" del joven es subsumido por el "yo colectivo", que piensa y actúa en forma alterna.

- Consumo de bebidas alcohólicas y drogas ilegales, como parte de la vida diaria de los integrantes, antes y durante el partido de fútbol.

\section{EL ESPECTÁCULO DE LA VIOLENCIA GENERA AGRESIVIDAD}

Existe una mediatización de las barras bravas; éstas aparecen en los medios de prensa escrita, televisiva, inclusive, brindando entrevistas. Investigaciones psicológicas concluyen que actos violentos tienden a estimular a agresividad de los espectadores (Arboccó y O'Brien, 2012). Es necesario que los medios de comunicación regulen esta escenificación de la violencia, muchos recurren a la explotación de las imágenes agresivas, luego aparece un doble discurso al quejarse de las mismas. Según Dunning y cols. (1982) constituyen un "amplificador de la violencia" porque exageran los hechos protagonizados por los "hinchas violentos"; para los barristas son hazañas con la cual consiguen "salir en la tele". En entrevistas a los "barra bravas" nos enteramos que coleccionan los informes de prensa sobre sus "aventuras delictivas".

Se brinda así un patrón para la imitación y cierto status entre sus seguidores.

\section{SUBCULTURAS VIOLENTAS ENTRE GRUPOS ESPECÍFICOS DE ADOLESCENTES Y JÓVENES:}

En un estudio de la década de los ochenta sobre este mismo tema, Van der Brug y Marseille (1993) en Holanda con 268 seguidores de 4 clubes de fútbol encontraron:

a) Edad de los espectadores violentos: entre los 16 y los 18 años. b) Estaban más interesados en la victoria que en el estilo de juego.

c) Provenientes de un nivel socio-económico bajo.

d) Con malas relaciones con los padres (quienes no pueden ejercer un control social sobre ellos).

e) Inadaptación en la escuela.

f) Resultaron también violentos en otras actividades y contextos no deportivos

Estas características no son ajenas a realidades como la nuestra, y encajan muy bien en investigaciones realizadas sobre las causas de la violencia juvenil y el pandillaje.

\section{SÍNTESIS DE ALGUNAS TEORÍAS DE LA VIOLENCIA (EN EL FÚTBOL):}

1. Conducta agresiva (Freud - Lorenz):

- Tendencia innata a la conducta agresiva (predisposición de estados fisiológicos).

2. Aprendizaje social:

- Aprendizaje de la agresión: observación, imitación y reforzamiento (ambiente social).

3. Teoría sociológica subcultural

Es una teoría que relaciona los comportamientos violentos con las desfavorables condiciones sociales y laborales de la clase menos favorecida; de tal modo que, cuando el fútbol se empieza a practicar como deporte en la clase obrera, se asume que éste les "pertenecía" y luego perciben que se va alejando de ellos por su profesionalización a mediados del siglo XX, por lo que se sienten apartados. Para reducir ese sentimiento, la clase obrera -el pueblo- intenta seguir controlándolo o, coprotagonizándolo, que sería más acertado. Así, al verse "inferiores" en el escalafón de la sociedad por su origen más humilde, intentan protagonismo y un reconocimiento social a través del fútbol que, aunque en un primer momento era solamente de apoyo al equipo, algarabía y fiesta, ha degenerado hasta los niveles de violencia a la que desgraciadamente ya nos vamos acostumbrando (Abraham, 1999). 


\section{¿EL SISTEMA ESTIMULA LA VIOLENCIA?}

- Una sociedad corrupta y una sociedad violenta e injusta es caldo de cultivo para pandillas y barras bravas.

- Sumamos a esto hogares destruidos, frustraciones, falta de oportunidades y una necesidad de pertenencia.

- Los medios de comunicación tienen diversos y variados efectos en las diferentes fases de la vida de una persona.

- Promoción de otras formas de violencia (películas, vídeo juegos).

- Asíla violencia se transforma en una compañera habitual, en una forma normal de vida y el único método para solucionar problemas $\mathrm{y}$ quizá destacar.

\section{CONSECUENCIAS DE ESTE FENÓMENO:}

- Exposición a la violencia y a los riesgos que estas conducen.

- Realizar un currículo delincuencial, de barra brava a ladrón, vendedor de drogas, extorsionador, secuestrador, asesino. De delincuente común a criminal organizado.

- Aumentan los niveles de tensión en el propio sujeto.

- Deserción escolar, vida académica nula.

- Pérdida de tiempo y ausencia de proyecto de vida.

- Daños materiales y humanos.

- Ausentismo a los estadios.

- Inseguridad ciudadana.

- Pérdidas económicas.

- Heridos leves.

- Heridos graves.

- Muertes.

- Exposición a consumo de sustancias adictivas y nocivas.

- "La seguridad como negocio": necesidad de pago a policías privados, empresas de seguridad, fabricantes de alambrados, vallas de contención y compra de armas.

\section{¿Existen soluciones?}

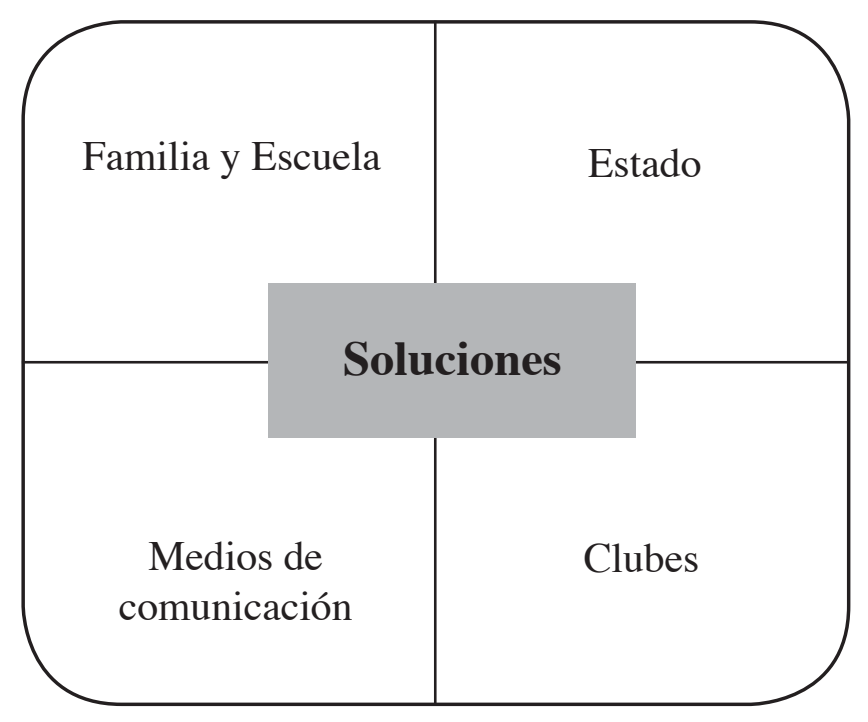

Gráfico 2: Agentes responsables de la solución al problema. Elaborado por los autores, 2013

\section{TENTATIVAS DE SOLUCIÓN:}

Es difícil acabar rápidamente con la violencia en el fútbol peruano pero sí se pueden combatir y reducir las circunstancias fatídicas. A continuación una serie de medidas preventivas y punitivas, muchas de estas medidas ya se vienen empleando en otros países con buenos resultados. Veamos:

1. Pérdida del partido (pérdida de puntos al equipo).

2. Separación de los clubes de torneos nacionales e internacionales, (un ejemplo es el caso del club Liverpool de Inglaterra que fue separado en el año 1985 de participar en torneos internacionales por los incidentes violentos en la final de la Copa de Europa del mismo año jugada en Bruselas donde enfrentaron a la Juventus de Italia y murieron 39 personas. El club inglés fue sancionado con el retiro por 10 años de los torneos internacionales (Luego la sanción fue reducida a 6 años).

3. Multas económicas al club.

4. Barra carnetizada. 
5. Leyes estrictas y que se cumplan: desde 1997 existe una Ley contra la violencia de barras deportivas pero rara vez se emplea por corrupción, dejadez, indiferencia o leguleyadas.

6. Educación: trabajar este tema y otros anexos con las familias y los colegios (Arboccó y O’Brien, 2012).

7. Cárcel para asesinos/delincuentes debidamente identificados.

8. Castigo a clubes y jugadores por coludirse con los malos elementos infiltrados en sus barras oficiales (un ejemplo: el jugador brasilero Roberto Carlos fue castigado por regalarle su camiseta a un aficionado de la barra fascista "Ultras Sur" del Real Madrid de España).

9. Prohibir la entrada a determinados individuos identificados.

10. Propuestas educativas que puedan facilitar una canalización de esa violencia (Calvo, 1998).

11. Programas psicológicos para fomentar la confianza y fortalecer autoestima en los jóvenes, por parte de las Municipalidades y entidades públicas y privadas (Arboccó y O'Brien, 2012).

12. Programas para rehabilitar a jóvenes integrantes de pandillas y "barras bravas" que puedan tener acceso a un empleo digno y a educación.

13. Endurecer las penas contra los delincuentes infiltrados en las hinchadas de fútbol.

14. Limitar la venta de alcohol en las afueras del estadio y especialmente en el contexto del partido. Existen estudios en ciertas realidades que plantean que el incremento del alcohol estimula la violencia en los jóvenes (OMS, 2006).

15. La capacidad de los estadios no debe ser rebasada (esto último ya se viene considerando).

16. Los medios de comunicación no deben acentuar la adversidad y animosidad entre los competidores ni glorificar la violencia, ya que esto la incita.

17. Los dirigentes deberán ser informados y obligados a romper acuerdos bajo la mesa con los "barras bravas".
18. Estadios más seguros / entradas, salidas, vías de acceso, separación de tribunas, cámaras de vídeo, incremento de la vigilancia (Allende Frausto, 2005).

19. Una policía mejor preparada con capacitación para estos casos especiales usando experiencias de casos en otros países. Muchos policías de "oficina" y "seguridad de locales" son llevados los fines de semana a operativos donde tendrán que enfrentarse a turbas de jóvenes excitados y alterados. ¿Podrán?.

\section{CONCLUSIONES FINALES:}

1. Las barras bravas responden a la clasificación de tribus urbanas, ya que potencian pulsiones relacionadas con el "ser gregario" implícito en el hombre. Las barras hacen sentir a sus integrantes incluidos en una unidad de orden superior.

2. Generan aspectos identitarios que les lleva a defender intereses comunes, estrechar los vínculos entre sí y se convierten en espacio propicio para poner en comunidad rituales y costumbres que con el tiempo van creando condiciones para la confidencialidad y la lealtad (Fernando Bolaños, 2007) así como la complicidad y demás contubernios.

3. Ante los problemas de identidad y rol social, muchos jóvenes hacen uso de actitudes incontroladas y violentas que arremeten contra todo rival sin respeto alguno a las normas sociales

4. La violencia en el fútbol no constituiría más que un reflejo de una sociedad violenta (Panfichi, 1999).

5. Los barra bravas se han constituido en un elemento de identidad, de poder que cohesionan y socializan, donde el arma no se oculta sino se luce para ser temido y admirado.

6. La policía, lejos de causar temor y respeto, es despreciada y atacada. Muchas veces provocan sin razón aparente y están involucradas en actos de corrupción con barras bravas. Se hace necesario capacitarla para enfrentar mejor esta problemática sin dejar de fomentar 
el espectáculo y entretenimiento de muchas personas que asisten al estadio para divertirse. Pretender que el fútbol se juegue sin moverse y en silencio también es un despropósito.

7. Los medios de comunicación intensifican la violencia en el fútbol y hacen un gran negocio de ella. Periodistas se involucran para fomentar, a través de comentarios y un propio hinchaje - que no pueden manejar y a veces encubrir - , a malos hinchas que suelen ser los que están detrás de graves denuncias. Les hacen notas de prensa y presentan como grandes personajes, situación que refuerza el status del "barra brava".

6. Existen dirigentes coludidos con las barras bravas que fomentan y encubren la conducta ilegal de los pseudo barristas. Denunciarlos es tarea de los periodistas deportivos.

7. Cambiar esta situación requiere un trabajo policial, dirigencial, mediático y educativo. Ya existen experiencias donde se ha podido frenar estas olas delictivas en el deporte del fútbol.

8. El problema de los desadaptados se da en todos lados, pero si la policía, los abogados y jueces, y la prensa no ayudan y se coluden en mantener intocables a los "barras bravas", entonces el problema continuará y se volverá inmanejable.

9. La problemática de la violencia en el futbol es una nebulosa de amargas consecuencias que no podrá ser resuelta a corto plazo. Todo hace indicar que hablamos de un problema que cohabitará en nuestra sociedad por años mientras exista la desidia y, a la complicidad de nuestras autoridades en general, les sea conveniente y haya quienes se beneficien de la misma. Problemáticas que vienen ocurriendo en otros países donde la extorsión y el chantaje de ciertos malos hinchas a dirigentes y jugadores se han vuelto algo real también en nuestro medio.

\section{REFERENCIAS:}

Abraham, T. (1999). Juego salvaje, en Clarín, Buenos Aires: 9/3/99.

Alabarces, P. (1996). Fútbol argentino: un cacho de culturas. En: Cuestión de Pelotas. Pablo Alabarces y María Graciela Rodríguez (eds.). Atuel. Buenos Aires. p. 17-33.

Allende Frausto, A.I. (2005). Agresividad y violencia en el fútbol. Revista Digital Universitaria de la UNAM. Volumen 6, Número 6. ISSN: 1067-6079

Arboccó, M. y O’Brien, J. (2012). Impacto de la televisión basura en la mente y la conducta de niños y adolescentes. Avances en Psicología, 2, pp. 43-57. UNIFÉ, Lima. Disponible en la dirección siguiente: http://www.unife.edu. pe/publicaciones/revistas/psicologia/2012/2/ Avances.Arbocco.5.pdf

Benavides, M., Castro, T., y Tong, F. (1998). Las barras bravas y la ausencia del gol. Entre comandos y trincheras. En: ¿Nacidos para ser salvajes? Identidad y violencia juvenil en los '90”. Maruja Martínez y Federico Tong (editores). SUR. CEAPAZ. Lima. p. 103 - 122.

Calvo, F. (1998). Asesinos, Traficantes y Delincuentes. Una campaña contra la violencia en el fútbol. Buenos Aires: Mimeo.

Dunning, E. \& cols. (1992). La violencia de los espectadores en los partidos de fútbol. En. N. Elias y E. Dunning. Deporte y ocio en el proceso de la civilización. México. Fondo de Cultura Económica pp. 295-322.

Fernando Bolaños, D. (2007). No más barras bravas... barras populares. Colombia: Revista Kinesis, número 46.

GarrigaZucal, J.(2006). Acá es así: hinchadas de fútbol, violencia y territorios. Facultad de Humanidades y Ciencias Sociales de la Universidad Nacional de Misiones. Tucumán: Argentina.

Mejía Navarrete, J. (2005). Medios de comunicación y violencia. Los jóvenes pandilleros en Lima. Revista Espacio Abierto, Cuaderno venezolano de Sociología, 3 (14), 389-404. 
Organización Mundial de la Salud. (2006). Violencia juvenil y alcohol. Ginebra, disponible en la dirección siguiente: http://www.who.int/violence_ injury_prevention/violence/world_report/ factsheets/fs_youth_es.pdf.

Organización Mundial de la Salud. (2006). Violencia interpersonal y alcohol. Ginebra, disponible en la dirección siguiente: http://www.who.int/ violence_injury_prevention/violence/world_ report/factsheets/pb_violencealcohol_es.pdf.

Ortega Olivares, M. (2008). Fútbol, barras y violencia. Actualidad en el deporte: Investigación y aplicación. Ponencia presentada en el XI Congreso de Antropología: retos teóricos y nuevas práctica celebrado en Donostia-San Sebastián, España, 1013 septiembre de 2008.

Panfichi, A. (1999). Representación y violencia en el fútbol peruano: barras bravas. En: Contratextos, 12. p. $151-161$.
Singer, R. (1975): El aprendizaje de las acciones motrices del deporte. Barcelona: Hispano Europea.

Romero, A. (1986). Muerte en la cancha. Argentina: Editorial Nueva América.

Van der Brug, H. (1993). Psicología del deporte. Conceptos y aplicaciones. Madrid: Ediciones Morata.

Zimbardo, P. G. (1969). The Human choice: Individuation, reason and order versus desindividuation, impulse an chaos. In W. J. Arnold y D. Levine. (eds.). Nebraska Symposium on Motivation. Lincoln. NA: University of Nebraska Press.

Fecha de recepción: 15 de julio 2013

Fecha de aceptación. 1 de octubre 2013 